\title{
Trabalho e trabalhadores dos canaviais: perfil dos cortadores de cana da região de Ribeirão Preto (SP) ${ }^{1}$
}

\author{
Leandro Amorim Rosa ${ }^{2}$, Vera Lucia Navarro ${ }^{3}$ \\ Universidade de São Paulo (Ribeirão Preto, SP)
}

\begin{abstract}
A cultura de cana-de-açúcar é uma das mais importantes atividades da agroindústria do Brasil e atualmente encontrase em expansão. $\mathrm{Na}$ agroindústria canavieira ocorreram mudanças no processo produtivo que, por um lado resultaram em aumento significativo da produtividade, competitividade e melhoria na qualidade dos produtos e, por outro, são relacionadas à maior precarização e intensificação do ritmo de trabalho. A pesquisa que resultou neste artigo teve por objetivo conhecer o perfil dos trabalhadores envolvidos nesta atividade e investigar as suas condições de trabalho no corte da cana-de-açúcar na região de Ribeirão Preto, SP. Foram entrevistados 13 trabalhadores, migrantes, empregados no corte da cana, um membro da Pastoral do Migrante de Guariba, SP, o presidente do Sindicato dos Empregados Rurais da mesma localidade e dois psicólogos funcionários da área de Recursos Humanos de uma usina processadora de açúcar e álcool da região pesquisada. Os dados obtidos demonstraram que os trabalhadores, em sua maioria migrantes, para serem contratados são avaliados segundo sua capacidade de produção, sua resistência física e sua subordinação aos superiores. O salário por produção implica a superexploração da força de trabalho que repercute nas condições laborais e de saúde dos trabalhadores.
\end{abstract}

Palavras-chave: Trabalho rural e saúde, Trabalho, saúde e migração, Colheita de cana-de-açúcar, Saúde do trabalhador rural.

Work and workers of sugar cane fields: profile of the cane harvesters of the region of Ribeirão Preto, São Paulo, Brazil

The cultivation of sugar cane is one of the most important activities for the Brazilian agribusiness and it is still in ascension. Changes occurred in the production progress of the sugar cane industry, which resulted, on one hand, in a significant increase in productivity, competitiveness and improving of the quality of the products, and on the other, in the increasing of job insecurity and the intensification of the work rhythm. The research that gave rise to this paper aimed to identify the profile of workers involved in this activity and investigate their conditions of work at the harvest of sugar cane in Ribeirão Preto, Brazil. Thirteen migrant workers in sugar cane fields were interviewed, as well as a member of the Pastoral Care of Migrants of Guariba, São Paulo, the president of the Rural Workers Union of the same locality, and two psychologists, employees of the human resources of a sugar and alcohol processing plant in the researched area. The data obtained demonstrated that the workers, mostly migrants, to be hired are evaluated according to their capacity of production, stamina and subordination to superiors. The wages based on production imply the over-exploitation of the workforce, which echoes in the workers conditions of labor and health.

Keywords: Rural work and health, Labor, Health and migration, Sugar cane harvest, Rural worker's health.

\section{Introdução}

O Brasil é hoje o maior produtor mundial de cana-de-açúcar, seguido por Índia, China, Tailândia e México (Schlesinger, 2008). A cultura da cana-de-açúcar no país, que se encontra em novo ciclo de expansão, se destaca como uma das mais importantes atividades da agroindústria nacional e tem recebido especial atenção internacional devido à possibilidade de se tornar fonte de matriz energética alternativa. $\mathrm{O}$ etanol produzido a partir da cana-de-açúcar é utilizado como combustível automotivo no Brasil desde a década de 1970 e, "recentemente, o país voltou a ser um grande consumidor de álcool combustível, devido à adoção da tecnologia flex-fuel nos motores dos automóveis, que permite a mistura de gasolina e álcool em qualquer proporção" (Schlesinger, 2008, p. 9).

1 Este artigo apresenta dados extraídos de pesquisa de Iniciação Científica desenvolvida por Leandro Amorim Rosa e orientada por Vera Lucia Navarro, com auxílio financeiro da Universidade de São Paulo - bolsa RUSP (Rosa, 2009).

2 Leandro Amorim Rosa . Programa de Pós-graduação em Psicologia da FFCLRP da Universidade de São Paulo.

3 Vera Lucia Navarro. Professora Associada do Departamento de Psicologia da FFCLRP da Universidade de São Paulo 
No Estado de São Paulo, a cana é responsável pelo maior valor de produção agrícola, o que correspondeu a cerca de R $\$ 26$ bilhões em 2011 segundo informações do Instituto de Economia Agrícola do Estado de São Paulo-IEA (2012), superando o segundo colocado, a carne bovina, cujo valor, no mesmo período foi de aproximadamente $\mathrm{R} \$ 6$ bilhões.

O interesse internacional nesse produto fica evidente a partir dos dados apresentados pelo IEA, no qual afirmam que a cana-de-açúcar foi responsável por 31,52\% (R 978 milhões) das exportações dos Agronegócios do Estado de São Paulo no primeiro trimestre de 2009 (IEA, 2012).

Este é um setor que também se destaca pela quantidade de trabalhadores empregados na área rural no país. No ano de 2006, apenas no Estado de São Paulo, o setor foi o responsável por mais de 96 mil postos de trabalho formais (Fredo, Otani, Baptistella \& Vicente, 2008).

Não é apenas o cultivo da cana que se encontra em expansão, é todo o complexo agroindustrial canavieiro, que inclui a produção agrícola e também a produção industrial, com destaque à produção de açúcar e álcool (etanol).

O agronegócio canavieiro hoje encontra-se em expansão, com expectativas de crescimento da produção de açúcar e álcool, o que tem colocado o país em posição de destaque no cenário internacional. Em 2010, foram produzidas, na região de Ribeirão Preto, mais de 40 milhões de toneladas de cana (IEA, 2012). Estima-se que o Brasil produza 100 bilhões de litros de álcool a partir de 2025, quatro vezes mais que o produzido em 2007 (Alves, 2008).

Além da expansão da área de cultivo, a agroindústria canavieira passou por mudanças no processo produtivo que resultaram no incremento da mecanização da produção, em especial a colheita/corte da cana, em significativo aumento de produtividade, no aumento da competitividade e na melhoria e qualidade dos produtos, mudanças que são integrantes da reestruturação tecnológica do capital sucroalcooleiro (Thomaz Júnior, 2002). Entretanto, essas mudanças também estão relacionadas à extinção de postos de trabalho, a maior precarização das relações e condições de trabalho, à intensificação no seu ritmo e no aumento do desgaste físico e mental dos trabalhadores. Se na década de 1950 cada trabalhador cortava, em média, três toneladas de cana/ dia, na década de 1980, este número chega a cerca de seis toneladas/dia e, ao final da década 1990 e início da década de 2000 a média exigida do trabalhador alcança as doze toneladas/dia (Alves, F., 2006). Segundo Palhares (2014), ainda persistem as condições de precarização do trabalho na colheita manual da cana-de-açúcar sendo que aumentou o esforço despendido pelos cortadores nos últimos 30 anos. Tal jornalista relata que em 2013 o Ministério Público do Trabalho apontou 63 investigações na região de Ribeirão Preto por supostas irregularidades trabalhistas.

O esforço excessivo necessário para desempenhar o trabalho no corte da cana-de-açúcar levaria ao aumento das doenças relacionadas a essa atividade e, até mesmo, aos casos de mortes de cortadores, como os documentados pela Pastoral do Migrante de Guariba, SP, que contabilizou, até 2009, 21 mortes que estariam relacionadas ao trabalho no corte da cana (Facioli \& Peres, 2007). A denúncia das mortes pela Pastoral do Migrante foi objeto de algumas audiências públicas, a primeira delas ocorrida em Ribeirão Preto no dia 4 de outubro de $2005^{4}$.

Contribui para a intensificação do trabalho, dentre outros fatores, o pagamento por produção e a queda dos preços da tonelada de cana cortada. Na década de 1980 , o trabalhador recebia em média $\mathrm{R} \$ 9,00 /$ t. de cana cortada, e em 2005, tal valor caiu para $\mathrm{R}$ 2,50 (Zanella, 2007).

4 Consta na Ata da audiência que seu objetivo foi o de "colher elementos para apurar os fatos que chegaram até o Ministério Público Federal para tratar das questões relacionadas à morte, até agora inexplicada, de trabalhadores rurais no setor de cana-de-açúcar e até agora não se sabe a causa dos óbitos. Sabe-se que na região ocorreram aproximadamente dez mortes. Causa estranheza, principalmente, que pessoas com pouca idade venham a morrer com o diagnóstico de "parada respiratória" Sérgio Gardenghi Suiama. Procurador Regional dos Direitos do Cidadão. Ata da audiência pública "Exploração da mão de obra temporária. Condições de moradia e alimentação. Submissão a esforço excessivo e à morte de trabalhadores rurais. Lavoura de cana-de-açúcar. Região de Ribeirão Preto - SP" Ministério Público Federal - Procuradoria da República em São Paulo - Procuradoria Regional dos Direitos do Cidadão. Recuperado em 4 de maio, 2013, de http://www.prsp.mpf.gov.br/prdc/area-de-atuacao/escravtraf/Ata\%20da\%20 Audiencia\%20Publica\%20realizada\%20em\%20Ribeirao\%20Preto\%20-\%20traba.pdf. 
Ao comparar a "evolução" salarial desses trabalhadores e os aumentos do salário-mínimo do Estado de São Paulo entre os anos 1986 e 2007, é possível verificar que a remuneração dos cortadores de cana teve forte desvalorização: em 1986, eles ganhavam o equivalente a 2,5 saláriosmínimos, valor que passou ao equivalente a 1,21 salário em 2007 (Alves, F., 2008).

As condições de habitação a que esses trabalhadores se submetem é outro agravante para suas já precárias condições de vida. Isso ocorre, entre outras coisas, pelo fato de grande parte deles ser composto por migrantes que não têm outra possibilidade de moradia (Silva, 2007).

Partimos do pressuposto que nem todo trabalhador consegue realizar o corte da cana-deaçúcar, à medida que esta atividade requer grande dispêndio de força física. Além disso, estes trabalhadores ao migrarem em busca de trabalho estão sujeitos, muitas vezes, à condições extremamente precárias de moradia, alimentação e saúde, entre outras. A pesquisa que resultou nesta publicação teve como objetivo contribuir com o conhecimento do perfil do trabalhador empregado no corte da cana-de-açúcar na região de Ribeirão Preto (SP). Para isso, buscou-se conhecer sua procedência, quais eram os atributos requeridos para sua contratação, se havia preferência por parte das usinas no recrutamento de trabalhadores de um sexo determinado, e também investigar suas condições de trabalho.

\section{Metodologia}

A fundamentação teórica e metodológica que embasa a pesquisa está ancorada no materialismo histórico dialético, que possibilita a apreensão da realidade a partir das suas múltiplas determinações.

Para Marx (1983), o concreto adquire significação por ser síntese de múltiplas determinações, é unidade do diverso. Nesta perspectiva o ponto de partida da investigação é a realidade que nos é dada a conhecer, aquela que é aparente - o concreto aparente. É necessário pois, ir além das aparências para se conhecer o real, como diz Marx, é preciso para isto descobrir o véu da produção.

No caso dos cortadores de cana, a realidade aparente, ou seja, aquela que nos é dada a conhecer empiricamente, é aquela que nos apresenta uma categoria de trabalhadores formada por homens jovens, fortes cujo valor de seus salários depende de seu empenho e esforço. À medida que se questiona esta aparência, buscando a essência das coisas nos deparamos com a questão de sua condição de migrantes, de terem deixado para trás família, amigos, terra natal em busca de trabalho para a sobrevivência. Quanto mais abstraímos o pensamento e buscamos o conhecimento do real vamos percebendo que a forma de remuneração, as condições e relações de trabalho, de moradia etc., daqueles trabalhadores revelam uma superexploração do trabalho, característica do processo de objetivação do capitalismo no país. A compreensão destas determinações permitem um olhar diferente para aquela realidade, para o concreto, que, ao final deixa de ser aparente e passa a ser um concreto pensado, por ser síntese de múltiplas determinações.

O cruzamento dos dados obtidos através de entrevistas com trabalhadores, membro da Pastoral do Migrante, representante sindical e funcionários da área de Recursos Humanos de uma usina, possibilitou uma compreensão mais aprofundada do problema investigado, que foi complementada pela bibliografia selecionada, boa parte dela referente a importantes pesquisadores do país de questões relacionadas à agroindústria canavieira e, em especial, ao trabalho na colheita da cana-de-açúcar.

A pesquisa, de cunho qualitativo, teve como principal instrumento de coleta de dados a entrevista, em coerência com autores que destacam a importância das fontes orais para pesquisa social (Bosi, 1979; Cedro, 2011). 
Foram entrevistados 13 trabalhadores, migrantes, empregados no corte da cana, um membro da Pastoral do Migrante de Guariba, SP, o presidente do Sindicato dos Empregados Rurais da mesma localidade e dois psicólogos funcionários da área de Recursos Humanos de uma usina processadora de açúcar e álcool da região pesquisada. Os trabalhadores entrevistados eram homens predominantemente jovens e com pouca escolaridade oriundos dos municípios de Timbiras, Chapadinha e Codó, no Estado do Maranhão.

As entrevistas eram semiestruturadas e abordavam, principalmente, temas relacionados à história de vida e trabalho dos cortadores de cana. A opção pela entrevista semiestruturada devese ao fato de que ela

(...) parte de certos questionamentos básicos, apoiados em teorias e hipóteses que interessam à pesquisa e que, em seguida, oferecem amplo campo de interrogativas, fruto de novas hipóteses que vão surgindo, à medida que recebem as respostas do informante. Desta maneira, o informante, seguindo espontaneamente a linha de seu pensamento e de suas experiências dentro do foco principal colocado pelo investigador, começa a participar na elaboração do conteúdo da pesquisa (Triviños, 1987, p. 146).

Preliminarmente foi realizada uma pesquisa exploratória com objetivo de mapear o campo empírico e colher informações acerca da realidade a ser pesquisada. Neste momento foram entrevistados três cortadores de cana residentes no município de Pradópolis, SP, cujo contato foi mediado por uma conhecida dos pesquisadores, moradora do bairro onde os trabalhadores residiam. As entrevistas, realizadas no local de moradia dos trabalhadores, foram gravadas e transcritas na íntegra. Os demais entrevistados residiam em Guariba, SP, e foram contatados por intermédio da Pastoral do Migrante daquele município.

Tendo em vista preservar a identidade dos entrevistados, a cada um deles foi relacionado um número. Os de número 1 a 10 foram entrevistados em Guariba nos anos 2008 e 2009; os de número 11, 12 e 13 foram entrevistados em Pradópolis, na fase exploratória da pesquisa. Os entrevistados RH1 e RH2 são dois psicólogos, funcionários da área de Recursos Humanos de uma usina sucroalcooleira da região pesquisada, cujas entrevistas foram realizadas em 2009.

A todos os entrevistados foi dada ciência dos objetivos da pesquisa e apresentado o Termo de Consentimento Livre e Esclarecido, por todos assinado.

\section{Origem dos trabalhadores e o processo de migração}

A grande parcela dos trabalhadores que migram para trabalhar nas regióes canavieiras do Estado de São Paulo é oriunda de regiões pobres do Maranhão, Piauí, Pernambuco, Bahia, Ceará, Alagoas, Minas Gerais (Vale do Jequitinhonha) e do Paraná. Segundo dados da Pastoral do Migrante de Guariba (SP) havia cerca de 200 mil trabalhadores migrantes temporários no interior do Estado de São Paulo em 2003 (Pastoral do Migrante, 2004).

Dada essa condição de migrante, os trabalhadores, muitas vezes chamados de os "de fora", são em diversas ocasiões estigmatizados pelos moradores ditos nativos da região ou cidade. Vettorassi (2007) afirmou que em Guariba ocorre um processo de "estigmatização" dos "de fora", que são marginalizados econômica, geográfica e socialmente. Tal marginalização se dá pela baixa renda, pelo local de moradia e pela rejeição e divisão social dos trabalhadores em relação aos "nativos".

A maioria dos entrevistados, em nossa pesquisa, se referiu à pouca oferta de emprego em sua região de origem como o principal fator da tomada da decisão de migrar em busca de trabalho no corte da cana, conforme se verifica no relato: "O trabalho lá é pouco. Não foi muito fácil não [deixar a família]. Mas tinha que vir, né?" (Entrevistado 2). 
Diante das dificuldades de alguns em se manterem enquanto pequenos produtores e da falta de trabalho assalariado em seus locais de origem, essas pessoas migram para a região Sudeste em busca de trabalho para garantir o seu sustento e o de suas famílias. O que se observa nas regiões de origem destes trabalhadores é que “(...) está havendo um processo de expulsão, ocasionado pela impossibilidade de os trabalhadores conseguirem boas terras para o plantio de subsistência e pela impossibilidade de acesso a outras formas de renda, por meio da venda da sua força de trabalho" (Alves, F. J., 2007, p. 47). O motivo da migração sazonal desses trabalhadores não se resume à falta de emprego, esta é uma questão muito mais complexa que se reporta à luta pela terra no país, ainda não resolvida. É sabido que em várias regiões, incluindo vastas áreas dos estados do Maranhão, Piauí, Bahia, de onde se originam os trabalhadores entrevistados nesta pesquisa os conflitos agrários são uma realidade e não estão livres de violência. A prática de expulsão através do uso da força bruta pelos jagunços encomendados é ainda realidade nestas regiões.

Os depoimentos da maioria dos migrantes revelaram que em suas regiões de origem no Maranhão ainda predomina a produção fundada na lógica do valor de uso, voltada para suprir as necessidades da família e o pequeno excedente produzido é vendido ou trocado entre parentes, amigos e vizinhos.

A viagem do Maranhão ao interior do estado de São Paulo dura cerca de três dias, é cansativa, perigosa e realizada, na maioria das vezes, em ônibus clandestinos, cuja passagem é mais barata. As condições de higiene tanto dos sanitários dos ônibus quanto daqueles disponíveis nos postos de paradas, bem como a alimentação são bastante precárias. Isso é observado no relato do Entrevistado 1: "Lá do Maranhão, de Chapadinha, pra vir pra cá, nós paramos só uma vez, só um dia pra almoçar. É quarenta e duas horas de viagem, mas não para”.

Na chegada o encontro com a nova realidade:

"Eu achava que era um pouco melhor né? (...) Agora você vem pra cá e vê que as coisas são bem diferentes. Uma hora falam que é uma coisa depois vai ver é outra, a gente tenta dar um jeito de ganhar, mas é muito pouco. (...) Muito do que nós ganha acaba ficando aqui mesmo”(Entrevistado 3).

"Foi triste, né [deixar a família]? Todo mundo chorando lá. É, mas tem que encontrar a vida em algum lugar. Por que lá não dá pra gente viver. Lá você vive no que é da gente mesmo. A gente cria bastante coisa. Aqui não, aqui é bem deferente. É tudo comprado, tudo é marcado também...” (Entrevistado 9).

Segundo nos foi relatado, migrantes que já trabalharam no corte da cana em outras ocasiões motivam seus colegas a virem também. "Ah, o pessoal que vem pra cá antes diz que dá pra ganhar um pouco aí a gente vem também" (Entrevistado 9).

\section{Por que contratar migrantes?}

Este é um questionamento importante da pesquisa que remete à questão da migração de trabalhadores rurais no país, tal discussão pode ser encontrada nos seguintes títulos referidos neste artigo: Alves (2007); Novaes, Conde, Maiane \& Zeitune (2007), Galiano, Vettorassi \& Navarro (2012); Novaes (2007); Silva (2007) e Thomaz Júnior (2002).

Há muito tempo que existe por parte das usinas a preferência pela contratação de trabalhadores migrantes. Esta preferência se dá principalmente por tratar-se de pessoas, simples, pobres, habituadas a lidar com trabalhos pesados, a viver em situações adversas, em geral possuem baixa escolaridade, são despolitizadas e, portanto, têm pequeno poder de negociação. Desta forma, aceitam se submeter às formas precárias de contratação e aos baixos salários. 
"A [a gente] não vem já contratado pela firma. A gente vem por conta própria (...) ficamos um mês parados. Não ficamos parados, porque ficamos trabalhando na rua [no canavial] por mês, avulso, na diária. (...) a gente já vem com pouco dinheiro, ficar parado não tem como” (Entrevistado 1).

Ou seja, esses trabalhadores, ao chegar a Guariba, não tinham nenhum vínculo empregatício garantido. Ao migrar, tais pessoas trazem consigo pouco dinheiro e, caso demorem para serem contratados, sua situação econômica, que já não era boa, se deteriora. Vale ressaltar que é necessário arcar com despesas de moradia e alimentação e, além disso, se preocupar com o compromisso assumido de enviar numerário para sustentar a família que ficou no local de origem.

Tais fatos explicam sua vulnerabilidade e a aceitação, sem contestação, dos baixos salários, das condições indignas de trabalho e moradia que lhes são "propostas" nos contratos de trabalho, ainda que estes sejam negociados coletivamente. Sobre esse tema, Alves (2007, p. 46) afirmou que

Por causa dessas condições, por serem migrantes de regiões distantes e pobres e, por serem resultado de um processo de expulsão em suas regiões de origem, não lhes é esperada qualquer manifestação de desacordo diante das exigências requeridas no processo de trabalho: em termos de produtividade e em termos de remuneração.

Para o corte manual da cana, ser jovem e ser migrante tornaram-se dois atributos altamente valorizados nesse segmentado mercado de trabalho. Explicando melhor: migrantes nordestinos, morando na periferia das cidades da região, em alojamentos coletivos, casas ou quartos alugados, vivendo totalmente voltados para o trabalho, são potencialmente mais produtivos. Isso porque ser trabalhador migrante significa estar sujeito ao controle do empregador para além do estrito tempo da produção. Contudo, entre tais trabalhadores migrantes ser jovem é outro aspecto diferenciador, o que não significa apenas ter força, resistência física, mas uma específica disposição para o trabalho alavancada pelo momento do ciclo de vida quando - via de regra - prevalece a busca, o desejo de "ser alguém na vida", motivação indispensável para os jovens enfrentarem a rotina e a disciplina no trabalho.

Afinal, para eles, filhos de agricultores nordestinos, o trabalho é o único caminho para a realização de projetos pessoais e familiares (Novaes, Conde, Maiane \& Zeitune, 2007). Isso pode ser verificado no seguinte relato: "É, a gente paga por mês aqui: aluguel, água, luz. Um pouquinho que sobra a gente põe na conta da gente e um pouquinho a gente manda pra família da gente" (Entrevistado 9).

É certo que "(...) o capitalista, em face da força de trabalho, exiba o mesmo comportamento que tem diante das outras mercadorias; quer comprá-la pelo preço mais baixo possível (...)” (Netto \& Braz, 2007, p. 103). Assim, o pequeno poder de negociação explica a preferência pelo uso da força de trabalho migrante em detrimento da força de trabalho local.

O relato de um dos trabalhadores entrevistados deixa transparecer a forma como os trabalhadores migrantes lidam com as dimensões positivas e negativas de seu trabalho: mesmo reconhecendo as dificuldades do trabalho que lhes são impostos, se mostram dispostos a se manterem empregados, deixando claro o quão pouco exigem em troca por sua força de trabalho.

"É... chega com um dinheirinho. Ajuda a família da gente. Coloca alguma coisinha que tem aqui, ajuda a mãe da gente. Bão. Mas aqui é sofrido demais, sofrido demais. Mas dá pra gente passar de boa, né? Não dá pra ganhar muito não, mas dá pra ganhar um pouco e viver de boa" (Entrevistado 9). 


\section{As condições de trabalho}

A jornada de um trabalhador no corte da cana-de-açúcar pode começar às 3 h e se estender até por volta das $17 \mathrm{~h}$, aí considerados o tempo despendido para o preparo das refeições antes de se deslocarem para as lavouras e os trajetos de ida e volta para o campo. Segundo os trabalhadores, há entre eles um revezamento para o preparo das refeições. A cada dia um dos membros do grupo se levanta mais cedo para preparar a refeição de todos. Para tanto, é necessário se levantar por volta das $3 \mathrm{~h}$, enquanto que os demais podem dormir até as $4 \mathrm{~h} 30 \mathrm{~min}$, dado que o ônibus que os buscam para levar às lavouras parte por volta das $5 \mathrm{~h} 20 \mathrm{~min}$.

A jornada de trabalho tem início às $7 \mathrm{~h}$ e por volta das $9 \mathrm{~h}$ o trabalho é suspenso por 10 minutos, quando recomeça até a hora do almoço. De forma geral, devido à falta de espaço para todos na barraca e nas mesas onde é feita a refeição, os trabalhadores são divididos em dois grupos: o primeiro deles faz sua refeição entre as $10 \mathrm{~h}$ e $11 \mathrm{~h}$ e o outro entre as $11 \mathrm{~h}$ e $12 \mathrm{~h}$. O trabalho é interrompido novamente por cerca de 10 minutos às $13 \mathrm{~h} 30 \mathrm{~min}$, retomado e, por fim, se encerra às 15h40min. O retorno ao "barraco", como os trabalhadores denominam seus locais de residência, ocorre entre as $16 \mathrm{~h}$ e $17 \mathrm{~h}$.

Os trabalhadores entrevistados afirmaram que sua produção diária varia de acordo com o tipo de cana cortada. Em média, eles dizem cortar de "de $100 \mathrm{~m}$ a $200 \mathrm{~m}$ " de cana e que ao cortarem cana ruim, referida como "deitada", a quantidade diminui para $50 \mathrm{~m}$ ou $60 \mathrm{~m}$.

De forma geral, os trabalhadores não sabem fazer a equivalência entre a quantidade de metros cortados e o peso equivalente em cana. Como a unidade de medida para o pagamento do corte da cana é a tonelada, os cortadores desconhecem a forma como é calculado o valor de seu salário, fato já reportado por Alves (2008) que relatou os artifícios usados na conversão entre metros, toneladas e reais pelas usinas, os quais impossibilita o controle do trabalhador sobre sua produção e prejudica a sua remuneração. Segundo este autor, "o pagamento por produção efetuado na colheita da cana foi cientificamente desenvolvido para que o trabalhador não saiba previamente quanto produziu e não possa controlar o seu pagamento e o seu processo de trabalho" (Alves, 2008, p. 37).

Alves (2008) afirmou que um trabalhador não só corta a cana e seu pendão, mas também a carrega até a rua central de seu eito, onde a arruma para ser transportada pelos caminhões da usina. Um trabalhador que corte $200 \mathrm{~m}$ de cana por dia caminha cerca de $5.700 \mathrm{~m}$, realizando entre 4 a 14 mil golpes de facão e flexões de pernas e costas.

O empreiteiro (conhecido por turmeiro ou gato) $)^{5}$ é o vínculo entre os cortadores e a usina e a remuneração daqueles, segundo os entrevistados, é diretamente relacionada com a produtividade de "sua turma", composta pelos trabalhadores que fiscaliza. É por conta desse fato que os trabalhadores afirmam que o gato acabe por exigir mais empenho dos trabalhadores, mesmo diante de situações nas quais os trabalhadores demonstram cansaço ou se queixam de dores, como demonstra o relato:

“(...) Ele [o gato] diz: 'rapaz, você tá doente? Rapaz, vamo embora trabalhar! Levanta, trabalha.' (...) E a gente morto fala: 'não posso, não posso'. E ele: 'vai trabalhar, vai trabalhar'. Quando a gente está com esses problemas [de muito cansaço] a gente vai para o busio [ônibus] por conta da gente." (Entrevistado 10).

5 Um Termo de Compromisso de 2009 - também conhecido como compromisso nacional para humanizar o trabalho na cana-de-açúcar - assumido por trabalhadores, empresários e Governo Federal previa, entre outras coisas, a substituição do gato pela contratação direta dos trabalhadores pelas empresas. Tal Termo possuía uma duração inicial de dois anos e, em 2011, foi prorrogado por mais um ano. Informações recuperadas em 03 de maio, 2014, de: http://www.secretariageral.gov.br/noticias/ ultimas_noticias/2009/06/not_260620092.

Segundo representante do Sindicato dos Empregados Rurais de Guariba, através de seu relato, a mediação realizada pelo gato entre os trabalhadores e as empresas ainda é uma realidade na região em 2014. 
A alimentação inadequada, somada às agruras deste tipo de trabalho considerado penoso e à pressão do "gato" pelo cumprimento das metas de produção repercutem diretamente nas condições de trabalho e saúde desses trabalhadores e se traduzem em esgotamento físico, tendinites, cãibras e problemas de coluna dentre outros.

\section{Capacidade de produção e desempenho, assiduidade, subordinação e condições de saúde: critérios de seleção da usina}

As entrevistas revelaram alguns dos critérios adotados pelas usinas para a contratação desses trabalhadores dentre os quais se destacaram o potencial para desempenhar tarefas e atingir metas, a submissão dos trabalhadores aos chefes, a boa saúde e o não questionamento às normas da empresa.

\section{Capacidade de produção e desempenho}

A produção dos trabalhadores envolvidos no corte da cana é mensurada em metros; no entanto, o pagamento pelo trabalho é feito com base no peso, medido em toneladas de cana cortada. Além disso, o valor do peso da cana cortada pode variar, dado que é influenciado pela dificuldade na realização do corte.

Durante a realização da pesquisa, tivemos acesso a um contrato de trabalho firmado entre o Sindicato dos Empregados Rurais de Guariba e a LDC Bioenergia S/A, com vigência entre maio de 2008 a abril de 2009. Nele, o piso salarial foi estabelecido em $\mathrm{R} \$ 557,00$ (quinhentos e cinquenta e sete reais)/mês, o que equivale a uma diária de $\mathrm{R} \$ 18,57$ (dezoito reais e cinquenta e sete centavos). Desta forma, um trabalhador que não recebesse o piso salarial teria que cortar cerca de seis toneladas de cana em pé de 18 meses queimada ou cerca de três toneladas de cana crua pé de rolo por dia para receber o equivalente ao salário-base.

A remuneração por produção, um dos mais perversos mecanismos de exploração desses trabalhadores, implica na intensificação do ritmo de trabalho e no maior desgaste do trabalhador. A existência de metas de produção que estabelecem o corte de 10 a 12 toneladas de cana ao dia, além de estimular a competitividade entre os trabalhadores em benefício das usinas, é também maneira "eficiente" de selecionar os mais aptos a suportarem este tipo de trabalho (Galiano, Vettorassi \& Navarro, 2012, p. 62).

Esse sistema de pagamento tem o apoio de grande parte dos trabalhadores, pois permite a eles receber remuneração significativamente maior que o piso salarial da categoria. Conforme se verifica no seguinte relato:

"Eu também acho [melhor] por produção. A produção torna mais fácil, melhor. Dá para tirar mais. Depende também do cara, entendeu? (...) Assim, quando o cara produz bastante, quando o cara é bom de cana, o salário é justo para ele, mas quando cara é ruim..." (Entrevistado 1).

Desta forma, pesa sobre o trabalhador a responsabilidade por sua remuneração, ou seja, ele acredita que é justo o fato de sua remuneração ser determinada pelo quanto ele trabalha.

Uma análise que não seja restrita à superfície do fenômeno social descrito desvelará muitas das relações ideologicamente encobertas. Como é característico do capitalismo, o empregador, no caso a usina, extrai uma parte do valor total gerado pelo trabalho do empregado, aqui representado 
pelo cortador de cana, ou seja, a mais-valia ${ }^{6}$. Assim sendo, a cada tonelada de cana cortada a empresa extrai uma determinada parte do seu valor para si, pagando o restante ao trabalhador. Por isso, quanto mais cana for cortada maior será a quantidade de valor que a usina extrairá para si. Ou seja, quem de fato ganha com o pagamento por produção é a usina. Assim, o trabalhador, na ânsia de aumentar seu rendimento, trabalhará com o máximo de suas forças e, muitas das vezes, em esforço excessivo. A empresa, por sua vez, não terá ônus algum, pois o aumento dos salários é acompanhado pelo aumento da mais-valia, o que gera apenas desejável valorização do seu capital.

Desta forma, é inadmissível para a usina o não trabalho, dado que é essa a única forma de não se realizar a mais-valia. $O$ seguinte relato evidencia tal questão: "O que eles não gostam muito é que o cara fique faltando muito assim. Isso a usina não gosta não. Porque aí não dão produção pra usina. Porque tem que dar produção pra ela, né? Aí não gosta [a usina] dá um acordo pro cara e o cara some (...)" (Entrevistado 9).

Como a quantidade de cana cortada varia de cortador para cortador e como a usina potencializa em muito os seus ganhos com os trabalhadores mais produtivos, a empresa se utiliza do critério produtividade para selecionar seus empregados. Quando questionado sobre o que é necessário para ser contratado o trabalhador responde: "Precisa cortar não sei quantas toneladas de cana aí. O cara tem que ser bom. Bom cortador, né?” (Entrevistado 7).

No entanto, demissões de funcionários contratados geram gastos ao empregador, que se vale do período de experiência de noventa dias para avaliar a produtividade dos trabalhadores. Durante o período de experiência o trabalhador deve cortar, no mínimo, o suficiente para pagar o seu piso salarial. No caso de a usina ter um excesso de contingente para o corte da cana ela realiza dispensas baseadas na produtividade dos trabalhadores.

\section{Subordinação}

Através das entrevistas realizadas em Pradópolis foi possível verificar casos de cortadores demitidos durante o período de experiência. Em um deles um trabalhador foi demitido no $88^{\circ}$ dia de trabalho, ou seja, dois dias antes de sua efetivação.

A interrupção do trabalho no corte da cana gera nos trabalhadores grandes impactos materiais e/ou subjetivos. Materialmente o trabalhador terá de retornar para casa sem aquele dinheiro que seria a principal fonte de renda da família durante a entressafra. Subjetivamente são quebradas suas expectativas, assim como as de sua família, como a esperança de se alcançar melhor nível de vida para si e para os seus familiares, assim como sua autoestima diante da suposta incapacidade de se manter no serviço até o final da safra, como se pode verificar nas palavras de um trabalhador demitido durante o período de experiência: "Nos outros anos ainda tenho me dado bem, juntado um bom dinheirinho, chegado em casa feliz. Esse ano é ano que vou chegar em casa... feliz, por ir para casa, mas chego sem nada" (Entrevistado 12).

Alves (2007, p. 46) abordou esse mesmo problema e afirmou que o trabalhador "(...) não pode retornar antes do final da safra e não pode retornar sem dinheiro, porque retornar nessas condições seria demonstrar publicamente, na origem, o fracasso".

O Entrevistado 12 relatou não saber a causa de sua dispensa. No entanto, um de seus colegas afirmou que a causa teve origem na recusa do trabalhador em entrar no ônibus que os transportava, o qual havia perdido os freios e estava com os faróis apagados, e no estímulo para que seus companheiros fizessem o mesmo. Ainda com o veículo nas condições relatadas, o fiscal

6 Conceito entendido como “(...) aquela parte do valor total da mercadoria em que se incorpora o sobretrabalho, ou trabalho não remunerado (...)” (Marx, 1983a), ou seja, o valor excedente produzido pelo trabalhador que é apropriado pelo seu empregador. Para mais informações sobre mais-valia consultar: (Marx, 1983a). 
queria que os trabalhadores retornassem à cidade nesse ônibus. Segundo a versão de seu colega de trabalho, o homem foi demitido por essa suposta insubordinação.

Assim como em Pradópolis, em Guariba também foi relatada a necessidade de se subordinar aos "superiores" sob pena de ser demitido ou não mais ser contratado, conforme se verifica no relato:

"Porque se a gente quer passar fixo a gente não pode reclamar de nada. Porque se reclamar ele [empreiteiro/gato] fica em cima da gente: 'Não é desse jeito não. É desse. Se vocês reclamarem alguma coisa de valentia vocês saem da usina sem direito, sem nada'. E a gente não diz nada" (Entrevistado $10)$.

Esse tipo de atitude da empresa, ou de seus prepostos, é possível, entre outras, devido ao fato de existir um grande exército de reserva de força de trabalho sem organização política, o que dificulta a mobilização desses trabalhadores. Desta forma, a usina se aproveita da situação selecionando aqueles que se enquadram no perfil físico e psicológico por ela requerido. Segundo Alves (2007, p. 40) "(...) as usinas perseguem maior produtividade, além de trabalhadores subordináveis ao chefe e fiscal da turma, que são os indicadores da contratação".

\section{Assiduidade e condições de saúde do trabalhador}

Outro critério utilizado para a seleção do trabalhador no corte da cana e facilmente identificável nas entrevistas é a sua assiduidade.

Dada a necessidade de produção da usina, esse critério é bem previsível. No entanto, a frequência do trabalhador é dependente de seu estado de saúde. Desta forma, as condições de saúde do trabalhador passam a ser, mesmo que indiretamente, critério de seleção quando de sua contratação.

Devido ao fato do pagamento do trabalho do cortador ser feito por produção, os trabalhadores em busca de melhor vencimento acabam por chegar, em muitos casos, à beira dos seus limites físicos. Tal esforço excessivo origina, muitas vezes, problemas como dores de cabeça, nas costas e, principalmente, cãibras. Alves (2007, p. 34), ao tratar deste assunto afirmou que:

A perda de água e sais minerais leva à desidratação e à frequente ocorrência de cãibras, que começam, em geral, pelas mãos e pelos pés, avançam pelas pernas e chegam ao tórax, acometendo todo o corpo (...). Essa cãibra provoca fortes dores e paralisia total do trabalhador semelhante a um ataque nervoso".

Os relatos dos trabalhadores demonstram a percepção que eles trazem do quanto essa atividade é nociva à sua saúde. Com menor capacidade de expressar o mal que lhes afetam, os trabalhadores são bastante precisos ao descrever o que sentem: "Prejudica. Quando força prejudica” (Entrevistado 8); "Se afeta a saúde? Tá doido? Afeta e muito!” (Entrevistado 7).

São comuns e frequentes as ocorrências de dores e de cãibras durante a jornada de trabalho. Sofrer com dores, cãibras, perder o apetite, vomitar são mazelas tão comuns que passaram a fazer parte da "normalidade" do trabalho, conforme se pode depreender do relato de um dos entrevistados: "Aí passa do limite da gente, não pode, já fica ruim já. Ai não come nada, vomita, dá câimbra. Mas é normal de se ver" (Entrevistado 9).

É possível "extrair" do relato dos entrevistados que o que importa é a satisfação da necessidade imediata de ganhar o seu salário, mesmo que isso signifique prejuízo à própria reprodução de sua força de trabalho. 
"Agora, dor no meu corpo eu tenho demais. Se fosse outra pessoa (...) passando mal pra caramba ficaria aqui. (...) Rapaz, é pior ficar no barraco. Porque se você não tiver um atestado médico, vão por falta pra você. E o que você vai ganhar? Não vai ganhar nada! Ai tua quinzena vem magra. Tem que ir. Tem que ir de qualquer jeito. Ou bom ou ruim tem que ir. Se o cara tiver passando muito mal aí o cara vai assinar lá o papel e fica no busio [ônibus] até a hora de ir embora” (Entrevistado 9).

"Dá assim em mim um problema que quando eu deito na cama dói demais... Aí eu peço a Deus para o dia amanhecer pra eu fica caminhando pra cima e pra baixo. Mas a gente tem que aguentar pra consegui uma condição melhor (...). Não dói as costas todo dia não porque eu tomo uns comprimidos. Aí alivia, né? Mas quando passa três dias sem tomar, torna a doer” (Entrevistado 10).

Mesmo quando o trabalhador necessita de atendimento médico hospitalar, não terminam suas agruras. A ida ao hospital pode revelar descaso e preconceitos. Conforme se verifica nos seguintes relatos:

"Adoece. Dá cãibra no corpo, as pernas da gente dói tudo aqui, os dedos da gente enrola (...). Dá uma gripe na gente apertada também, sai água dos olhos" (Entrevistado 10).

"Vixi, quando o cara corta demais, passa dos limites. Ai começa dar cãibra, aqueles enjoos pra vomitar. O sol muito quente, começa dar cãibra em toda parte do corpo, nossa! Fui até pro hospital. Forcei muito. [Deu cãibra] aqui (mostra a perna). E enjoou também. [No hospital] me passaram só um soro só. Ah, sei lá, acho que aqui o pessoal não gosta muito de baiano não. Eles não ligam muito não"(Entrevistado 1).

Mais do que a discriminação dos "da terra", é interessante notar que o cortador, um maranhense, se autointitula "baiano", forma preconceituosa e pejorativa que é costumada ser dirigida aos migrantes. É possível, a partir desse discurso, inferir que o próprio migrante pode ter assumido o papel social "inferior" que os "nativos" lhe atribuíram. Tal trabalhador deixa sua casa para trabalhar em condições extremas - trabalho esse que não seria executado por trabalhadores locais segundo informações da Pastoral do Migrante -, é desapropriado do valor que produz e esse valor gera uma riqueza que não lhe pertencerá, nem a ele nem à sua comunidade de origem. Esse trabalhador é discriminado e humilhado na terra em que cria riqueza alheia e perde a própria saúde. Desta forma, esses migrantes “(...) deixam de ser camponeses em regióes de economia pré-capitalista e tornam-se, definitivamente, peça fundamental para o avanço da reprodução do capital em áreas de economia capitalista consolidada” (Vettorassi, 2007, p. 152).

Nesse sistema de trabalho, conforme relato do trabalhador: "Chega ruim. Borrado eles chamam (...). É uma ressaca assim (...). Tem gente que vai quase morto pro hospital” (Entrevistado 8). Os próprios trabalhadores definem "borrar":

"É quando dá essas cãibras. Coisa ruim moço! Coisa ruim demais (...). O coração da gente fica voc, voc, voc. $\mathrm{O}$ ouvido da gente parece que vai estourar. Ai a gente tem que parar (...). O coração da gente fica batendo ligeiro: tan, tan, tan. A gente passa a mão aqui na gente pra vê se melhora. Ai tem que sentar" (Entrevistado 9).

Novaes (2007, p. 107-108) entrevistou um médico sobre as cãibras:

Quando o trabalhador é submetido a uma carga de trabalho e seu físico não está acostumado, e se ele estiver debilitado ou se portador de uma doença preexistente, uma cardiopatia, ele pode ter uma morte súbita se submetido a trabalho excessivo com sudorese. A transpiração excessiva 
provoca perda de eletrólitos, de sais do organismo. Se você pegar a camisa de um trabalhador ela chega a estar branca por causa da perda de sais. A câimbra é o primeiro sintoma de quando você tem distúrbio hidroeletrolítico. A câimbra é acúmulo de ácido lático na musculatura. Ele fica todo contorcido, parece um possuído. Pra você ter uma ideia, é quase como uma convulsão. E dói, dói muito aquilo. Um jogador de futebol, um atleta preparado quando tem câimbra ele é substituído. Imagine um trabalhador rural que se submete a uma rotina dura de trabalho. $\mathrm{O}$ tratamento correto é a hidratação com soro fisiológico (...). Eu nunca presenciei uma morte súbita por decorrência de distúrbio hidroeletrolítico, de câimbra. Geralmente, a pessoa chega morta no pronto-socorro.

Além do desgaste relacionado ao excesso de esforço, há também relatos de acidentes de trabalho, principalmente cortes nas mãos e pés produzidos pelo facão. Segundo Novaes (2007, p. 6), "nesse patamar de produção os riscos de acidentes de trabalho aumentam, pois o corpo extenuado perde a precisão dos golpes do facão na cana, e as pernas e a mão involuntariamente viram alvos".

É comum na região a distribuição aos trabalhadores de um tipo de energético, denominado repositor hidroeletrolítico, que ajuda a prevenir cãibras? ${ }^{7}$ Verifica-se que sob a máscara da preocupação com a saúde do trabalhador, se esconde a necessidade de manter ou ainda aumentar a produção. Ao utilizar tais repositores, ou sorinhos como é mais comum serem referidos, os cortadores aumentam a capacidade de seu corpo suportar um esforço que não deveria ser suportado, dado que os sinais de exaustão serão atenuados. Tal esforço pode acarretar problemas de saúde já citados, como dores musculares e na coluna, bursites, tendinites, entre outras (Novaes, 2007).

Quando questionados sobre a utilidade do repositor que utilizam, os trabalhadores afirmaram que: “(...) não é pra cortar mais, é para não cansar” (Entrevistado 1).

Alguns trabalhadores preferem não usá-los e um dos entrevistados relatou que o "sorinho" lhe provocou vômitos por duas vezes.

O uso dos repositores, oferecidos pela usina, pode passar a imagem de que a empresa tem uma política de preservação do bem-estar do trabalhador. Não se pode, de fato, saber quais as intenções de quem os fornece mas, é certo, que seu uso faz com que se amplie a produção do cortador: "Quando você força muito você consegue, dá cãibra. Aí dá energia você tomar ele [repositor] ao meio-dia. (...) não dá cãibra no corpo e você consegue trabalhar todo dia” (Entrevistado 1).

Relatos como este deixam transparecer a preocupação, por parte do trabalhador, em não conseguir trabalhar o dia todo ou os demais dias, dado que a falta ao trabalho pode determinar a "perda do dia", o que reduz seus rendimentos. $O$ trabalhador que se ausenta do trabalho por problemas de saúde tem o direito de receber a diária quando apresenta atestado médico. No entanto, a ausência do trabalhador, mesmo que justificada, é um dos critérios utilizados pela usina para a seleção de trabalhadores para a próxima safra, fato confirmado pelo relato de um dos entrevistados:

"Porque se esse ano eu venho e boto muito atestado, se tiver muito atestado, muita falta, aí no próximo ano, se eu vir, ela [usina] não quer mais, não consigo pegar mais porque estou faltando muito" (Entrevistado 1).

"(...) o cara que já trabalhou na usina responde muito para o fiscal, que responde para o turmeiro, que falta bastante, que tem muito atestado, aí eles já têm os dados deles todos. Aí leva a carteira, às vezes nem pega, vai assinar a carteira eles falam que não passou" (Entrevistado 1).

7 De acordo com informações obtidas oralmente com o representante do Sindicato dos Empregados Rurais de Guariba, SP, tal prática ainda ocorre na região na safra de 2014. 
Novamente é possível perceber a facilidade que a empresa tem para selecionar exatamente o perfil de trabalhador que lhe é mais rentável, com boa produção, subordinado e com condições físicas que lhe permite aguentar o trabalho durante toda safra sem faltas. Os trabalhadores, cientes de tais critérios, se sentem pressionados a alcançá-los, tornam-se dóceis com seus superiores, se esforçam ao máximo na produção e, em alguns casos, ignoram seus limites físicos, trabalhando muito quando não deveriam. Fica claro que jornadas de trabalho como as aqui relatadas "usurpa[m] o tempo para o crescimento, o desenvolvimento e a manutenção sadia do corpo (Marx, 1983b, p. 211)”.

\section{Recursos "humanos"}

Uma entrevista realizada com os funcionários do setor de Recursos Humanos de uma usina do mesmo grupo daquela que emprega os trabalhadores entrevistados em Guariba abordou temas diversos, dentre eles a questão do vínculo de emprego dos cortadores com a usina.

"Olha, do meu ponto de vista eu acho bem humanizado aqui na empresa. Se você for ver em outras usinas muitas vezes esse serviço é terceirizado. Muitas vezes você vê condições não adequadas ao serviço, ou práticas de terceiros ou da usina, e talvez a usina não tenha uma ligação. No nosso caso eles são nossos funcionários, então tem todo um trabalho e acompanhamento desse funcionário rural, toda essa questão do meio social, de atendimento mesmo, então nós temos todos os serviços abertos para estes funcionários. Eu acredito que a empresa tenha essa preocupação social” (RH1).

O funcionário entrevistado fez a defesa da relação "humanizada" que a usina tem com os cortadores de cana, fato visto de outro ponto de vista pelos trabalhadores:

"Com o pessoal da usina não tem relação nenhuma. Só com o empreiteiro mesmo que leva a gente pra trabalhar" (Entrevistado 7). "A gente vai pra palestra lá [na usina]. A gente nem fala muito bem com eles [pessoas da usina] não. É mais o fiscal que fica na roça e fala como é que é e não é...” (Entrevistado 9).

A existência de um "empreiteiro" ou fiscal faz com que os cortadores se sintam muito mais empregados daqueles prepostos que da própria empresa. O sentimento dos trabalhadores é corroborado pelo relato de um dos entrevistados do setor de $\mathrm{RH}$ :

"Como funciona? É o turmeiro que é o instrumento chave na contratação do trabalhador rural, é ele que faz o agenciamento para contratação desse pessoal, ou seja, ele traz para nós as pessoas que ele gostaria que trabalhassem com ele. E a gente faz essa entrevista com todos, é claro que não tem a possibilidade de fazer uma entrevista psicológica totalmente estruturada com essas 1.500 pessoas em dois meses, então o que a gente faz é ver as condições básicas. Então se é identificada alguma questão que é mais comprometedora a gente indica para aquele turmeiro o que nós identificamos, e cabe a ele excluir aquela pessoa do processo" (RH2).

Ou seja, o verdadeiro contato do trabalhador rural é com o "seu" turmeiro e é essa autonomia de ação dada pela empresa aos fiscais que justifica o medo dos cortadores de desobedecê-los ou desrespeitá-los, dado que deles depende a contratação ou dispensa dos funcionários.

Aparentemente, a usina cobra dos turmeiros apenas a produção de sua turma sem definir a forma que será utilizada para alcançá-la. Assim os turmeiros podem agir à sua maneira para potencializar a capacidade produtiva de sua turma, mesmo que isso implique que os meios de "incentivar" os trabalhadores transformem-se em ameaças e assédio moral, como os já relatados. 
Os funcionários da área de RH da usina ratificam as palavras dos trabalhadores a respeito dos critérios de seleção dos cortadores da cana-de-açúcar:

"A gente só não contrata se eles tiverem tido algum problema grave, ou de desempenho, ou de comportamento, ou de produção. Então, ele realmente não vai ter o retorno" (RH1). "Mas, às vezes, quando tem algum problema eles chegam a vir de Minas, da Bahia, e chega aqui ele já foi avisado que não tinha retorno e isso é geralmente por quê? Ou desempenho, relacionamento, falta demais" (RH1).

Por "retorno", entenda-se o emprego para determinado trabalhador no próximo ano, ou seja, se esse migrante aceitar, ele voltará para Guariba na safra seguinte já contratado pela usina.

Um dos argumentos da "humanização" da usina pelos entrevistados dos setores de RH é a questão da moradia dos trabalhadores:

"Bem, são os funcionários que escolhem o local [de moradia], e a empresa na hora da contratação faz uma visita ao local que eles escolheram. Muitas vezes acontece de eles escolherem um que não oferece qualidade de higiene, coisas básicas. Então a empresa aprova ou não a moradia. Caso não [aceito], ele é convidado a morar em outro local" (RH1).

Tal ponto de vista não é compartilhado pelos trabalhadores:

“Tem barraco que eles não querem que os cortadores deles morem. Tem barraco aí que não é aquele luxo, mas tem barraco que é bem pior. Barraco bem pior que esse aqui, aí eles não aceitam (...). Não [dão dinheiro para alugar um melhor]. Esse aqui é a gente mesmo que arruma pra gente. (...) Esse aqui passou. $\mathrm{O}$ que não passou aí eles não aceitam. Tem que mudar de barraco (...). Aí [se você não tiver dinheiro para pagar um melhor] tem que dar um jeito. Tem que dar um jeito nele. $\mathrm{O}$ turmeiro tem que dar um jeito de achar um barraco melhor (...). [A usina] não aceita não. $\mathrm{O}$ cara tem que achar um barraco melhor pra ele"(Entrevistado 8).

Na realidade se observa que a usina teme multas decorrentes de ações fiscalizatórias de órgãos governamentais e publicidade negativa ${ }^{8}$. Desta forma a usina, por não ter planos de auxílio à moradia para os migrantes (as despesas com a moradia são de integral responsabilidade dos trabalhadores), transfere a eles o ônus de se instalarem em "barracos" melhores.

Outro mote dos funcionários do setor de RH é que "humanizar" não é o bastante para a empresa, é preciso provar a eficiência desse processo:

"Na parte de seleção, querendo ou não a gente está em uma empresa que tem um objetivo comum: gerar lucro. Como? Estimulando alguém. Mas como você vai fazer que alguém trabalhe bem, satisfeito, motivado? Então a gente acaba entrando mais no processo psicológico de seleção, pra olhar desempenho, se trabalha com qualidade. Mas também não adianta eu pensar em número sem a pessoa ter um objetivo, um significado do trabalho. Acho que ele tem que ter essa noção do que ele

8 É comum, a cada início de safra, quando a fiscalização se acirra, as denúncias referentes às péssimas condições de moradia que trabalhadores migrantes estão submetidos. Recentemente, agosto de 2013 "O Ministério Público do Trabalho ajuizou ação civil pública em que cobra uma indenização de R\$ 800 mil da multinacional LCD (Louis Dreyfus Commodities) em razão dos trabalhadores flagrados em condições precárias de habitação em um distrito de Pedregulho (437 km de São Paulo). Uma blitz do Ministério do Trabalho e Emprego e do Ministério Público do Trabalho flagrou um grupo de migrantes nordestinos em condições consideradas precárias de habitação em um distrito da cidade. Um casal, por exemplo, foi encontrado morando em um antigo galinheiro" (Coissi, 2013). 
veio fazer e onde o trabalho dele vai chegar. Não é vir trabalhar sem vontade e acabou. É questão de saúde mental, né?" (RH1).

"[Para provar que a humanização traz resultados objetivos] Tem que ser com resultados no trabalho mesmo: de produção, desempenho" (RH1).

Fica claro que a "humanização" se justifica quando consegue-se potencializar a produção dos trabalhadores. Produção essa que, via de regra, é potencializada por meio de posturas "não humanizadas" como baixos salários, pagamento por produção, coerção etc. Desta forma é pouco provável a realização de mudanças por parte da empresa no que tange à organização do trabalho.

É interessante a forma como os funcionários da área de RH da empresa se apropriam do termo e defendem a necessidade de "humanizar" as relações de trabalho. Segundo Mészáros (1996), diante do avanço dos conflitos sociais, a ideologia dominante, para não perder sua hegemonia, se adapta à nova realidade. "Dessa maneira, as ideologias adaptadas às novas circunstâncias podiam pretender uma postura levemente crítica em face das manifestações superficiais do sistema em crise, sem sujeitar à crítica real os antagonismos internos fundamentalmente explosivos da ordem estabelecida" (Mészáros, 1996, p. 72). Ao que tudo indica, ao menos no que se refere à questão dos trabalhadores migrantes, não está ocorrendo uma ruptura ideológica, mas sim, adaptação e consequente revitalização da ideologia dominante.

\section{Considerações finais}

Os trabalhadores entrevistados, predominantemente homens, jovens e com pouca escolaridade, eram todos originários do Estado do Maranhão. A maioria deles lá vivia em condições socioeconômicas muito desfavoráveis e sob relações de trabalho que não podem ser considerados propriamente capitalistas. A migração, assim, deve-se primariamente à busca de melhores condições de vida para si e suas famílias e é necessário ressaltar que foram para cá trazidos por empreiteiros, a maioria sem contrato formal de trabalho.

Do fato de serem predominantemente homens de pouca idade pode-se inferir que o sexo e faixa etária estejam, se bem que não explicitamente, relacionados às exigências de contratação das usinas.

Os principais critérios de seleção relatados para o trabalho no corte da cana foram a "boa conduta" ou subordinação, a assiduidade, a manutenção de boas condições de saúde durante toda a safra e o alcance dos níveis de produtividade exigidos, o que praticamente restringe o emprego a homens fortes e sadios, mesmo havendo exceções.

No que se refere às condições de trabalho desses migrantes, foi verificado que mesmo os "avanços", como melhores equipamentos e moradia, podem ser identificados como potencializadores da produção dos cortadores, o que nos leva à constatação que mesmo as vitórias na luta por um trabalho menos precarizado foram incorporadas pelo patronato como forma de se aumentar a produtividade do trabalhador.

A questão da segurança no trabalho no corte da cana é muito precária, ainda que haja obrigatoriedade das empresas disponibilizarem os Equipamentos de Proteção Individual - EPIs é sabido que na prática isto nem sempre acontece. Os trabalhadores relataram, por exemplo, que usam botas totalmente desgastadas, inadequadas para o trabalho, muitos improvisam suas vestimentas a fim de se proteger do sol e das folhagens da cana. Também não lhes são fornecidos filtros solares, o que é uma necessidade para proteção da pele já que o trabalho é realizado a céu aberto sob sol escaldante. 
Sobre a situação dos cortadores de cana Oliveira (2007, p. 8) nos diz o seguinte: “(...) foram vidas consumidas por uma exploração tão cruel que custa acreditar que seus beneficiários são homens; bestas seria um termo mais apropriado para designá-los".

O trabalho no corte da cana pode ser caracterizado como alienado e brutalizante. Fundamentados em Marx, Andery e Sério (1988, p. 416) destacaram que a alienação se mostra parcialmente "ao produzir de um lado, o refinamento das necessidades e de seus meios, enquanto que de outro produz selvagerismo bestial, simplicidade plena, brutal e abstrata de necessidades; ou melhor, simplesmente, se faz renascer num sentido oposto".

É possível perceber facilmente a oposição existente entre esse modo de ser do trabalho e o trabalho em sua origem radical, que "(...) permite o salto do ser meramente biológico para o ser social” (Organista, 2006, p. 127). O trabalho, em sua radicalidade, é inclusive relacionado diretamente à liberdade.

(...) para Lukács, a liberdade se constitui em um processo gestado no e pelo trabalho que transforma o homem (sociedade) e a natureza, como também, num momento mais complexo de exigências constituídas originalmente pelo ato laborativo, em que estas se transferem da relação homem (sociedade) e natureza, para as transformações entre os homens - intersubjetividade (Organista, 2006, p. 145).

Dado o exposto, de que forma seria possível esses trabalhadores desfrutarem do trabalho com suas características primordiais ou, pelo menos, estarem mais bem protegidos contra tamanha exploração? Antunes (1999, p. 246-247) aponta um possível caminho:

Uma vida cheia de sentido em todas as esferas do ser social somente poderá efetivar-se através da demolição das barreiras existentes entre tempo de trabalho e tempo de não-trabalho, de modo que, a partir de uma atividade vital cheia de sentido, autodeterminada, para além da divisão hierárquica que subordina o trabalho ao capital hoje vigente e, portanto, sob bases inteiramente novas, possa se desenvolver uma nova sociabilidade, onde a ética, arte, filosofia, tempo verdadeiramente livre e ócio, em conformidade com as aspirações mais autênticas, suscitadas no interior da vida cotidiana, possibilitem a gestação de formas inteiramente novas de sociabilidade, onde a liberdade e necessidade se realizem mutuamente.

A nova sociabilidade, defendida por Antunes (1999), pode e deve ser antecedida por atuações políticas determinadas que podem ser implementadas a curto e médio prazos.

Silva (2007) cita possíveis pontos de discussão, que podem modificar a atual realidade desses trabalhadores. Entre eles estão: a necessidade da construção de uma unidade política que englobe as diversas representações coletivas dos trabalhadores (sindicatos, Pastoral do Migrante, Ministério do Trabalho etc.), unindo-os independentemente de suas origens; a obtenção da força política para obrigar a aplicabilidade do PAS (Fundo de Assistência Social) ${ }^{9}$ e a "(...) luta pela Reforma Agrária, sobretudo nas áreas de origem dos migrantes. Nesse sentido, haveria a diminuição da oferta de mão de obra para as empresas e, consequentemente, a imposição de novas relações de trabalho" (Silva, 2007, p. 81).

Podemos pensar também que,

A curto e médio prazos são necessárias mudanças que impliquem no enfrentamento da questão agrária. Ainda que nos limites do capitalismo, é urgente o estabelecimento de uma efetiva reforma

9 Segundo Silva (2007, p. 81), a Lei Federal n 4.870, de dezembro de 1965, (...) prevê que os municípios onde há plantação de cana e usinas de açúcar e álcool recebam, respectivamente, $1 \%$ do faturamento da cana, $1 \%$ do açúcar e $2 \%$ do álcool”. 
agrária no país que permita àqueles trabalhadores que migram em busca de trabalho a possibilidade de fixarem-se em seus locais de origem, onde possam trabalhar a terra regidos por outra lógica que não esta que determina o sucateamento de sua força de trabalho na agroindústria canavieira. A longo prazo, não podemos perder de vista que será somente em uma sociedade onde o trabalho não seja meio por excelência de exploração, de dominação de uma classe sobre a outra que se construirá uma nova sociabilidade firmada como fonte de criação, de prazer, de humanização, onde não haja espaço para aceitação dessas formas vis de exploração (Rumin, Navarro \& Perioto, 2008, p. 205).

Mesmo reconhecendo a extrema importância das propostas já abordadas no que se refere à melhoria das condições de trabalho de milhares de pessoas, deve-se pensar ações que as superem no sentido da busca por uma sociedade com relações de produção totalmente diversas das hoje existentes.

A formação histórica predominante do trabalho hoje tem como objetivo a valorização do capital. Entretanto não podemos esquecer que "(...) o trabalho concreto, produtor de valor de uso, é uma atividade ineliminável em qualquer forma de organização social; portanto, a sua existência independe da forma histórica concreta, por outro lado, a existência e a ampliação do capital não podem ocorrer sem o trabalho" (Organista, 2006, p. 145).

Assim sendo, o trabalho pode e deve se libertar das amarras do capital que atualmente o controlam. Somente tal transformação das relações de produção pode fazer com que o trabalho e, consequentemente, a humanidade, possa vislumbrar um grau de liberdade que até então lhes têm sido negado.

\section{Referências}

Alves, F. (2006). Por que morrem os cortadores de cana? Saúde e Sociedade, 15(3), 90-98. Recuperado de 27 de julho, 2013, de http://www.scielo.br/pdf/sausoc/v15n3/08.pdf

Alves, F. (2008). Trabalho e trabalhadores no corte de cana: Ainda a polêmica sobre o pagamento por produção e as mortes por excesso de trabalho. In M. A. M. Silva, F. Alves \& J. C. A. Pereira, Agrocombustíveis solução?: A vida por um fio no eito dos canaviais (pp. 22-48). São Paulo: CCJ-Centro de Capacitação da Juventude.

Alves, F. J. C. (2007). Migração de trabalhadores rurais do Maranhão e Piauí: Será esse um fenômeno casual ou recorrente da estratégia empresarial do complexo agroindustrial canavieiro? In J. R. Novaes \& F. J. C. Alves (Orgs.), Migrantes: Trabalho e trabalhadores no complexo agroindustrial canavieiro (os heróis do agronegócio brasileiro) (pp. 22-54). São Carlos, SP: EdUFSCar.

Andery, M. A. \& Sério, T. M. A. P. (1988). A prática, a história e a construção do conhecimento: Karl Marx. In M. A. Andery, N. Micheletto, T. M. P. Sério, D. R. Rubano, M. Moroz, M. E. Pereira, S. C. Gioia, M. Gianfaldoni, M. R. Savioli \& M. L. Zanotto, Para compreender a ciência: Uma perspectiva histórica (3a ed., pp. 402-430). Rio de Janeiro: Espaço e Tempo.

Antunes, R. (1999). Os sentidos do trabalho. São Paulo: Boitempo.

Bosi, E. (1979). Memória e sociedade: lembranças de velhos. São Paulo: T.A. Queiroz.

Cedro, M. (2011). Pesquisa social e fontes orais: particularidades da entrevista como procedimento metodológico qualitativo. Perspectivas Sociais, 1(1), 125-135. Recuperado em 05 de março, 2014, de http://periodicos.ufpel. edu.br/ojs2/index.php/percsoc/article/viewFile/2341/2193

Coissi, J. (2013, 7 de agosto). Blitz flagra trabalhador rural morando em ex-galinheiro em Pedregulho. Folha de São Paulo, Caderno Cotidiano. Recuperado em 02 de setembro, 2013, de http://www1.folha.uol.com.br/cotidiano/ ribeiraopreto/2013/08/1322945-blitz-flagra-trabalhador-rural-morando-em-ex-galinheiro-em-pedregulho-shtml

Facioli, Ir. I. \& Peres, Pe. G. (2007). Histórico dos cortadores de cana mortos no setor canavieiro. Pastoral do Migrante. Recuperado em 11 de dezembro, 2012, de http://www.pastoraldomigrante.org.br/index.php?option=com_conte $\mathrm{nt} \&$ view $=$ article $\& \mathrm{id}=44$ :historico-dos-cortadores-de-cana-mortos-no-setor-canavieiro-\&catid=47:memoria 
Fredo, C. E., Otani, M. N., Baptistella, C. S. L. \& Vicente, M. C. M. (2008). Recorde na geração de empregos formais no setor agropecuário paulista em 2006. Análises e Indicadores do Agronegócio, 3(2). Recuperado de 12 de abril, 2008, de http://www.iea.sp.gov.br/ot/verTexto.php?codTexto=9194

Galiano, A. M., Vettorassi, A. \& Navarro, V. L. (2012). Trabalho, saúde e migração nos canaviais da região de Ribeirão Preto (SP), Brasil: O que percebem e sentem os jovens trabalhadores? Revista Brasileira de Saúde Ocupacional, 37 (125), 51-64. Instituto de Economia Agrícola do Estado de São Paulo. (2012). Banco de Dados. Recuperado em 11 de dezembro, 2012, de http://www.iea.sp.gov.br.

Marx, K. (1983). Contribuição à crítica da economia política. São Paulo: Martins Fontes.

Marx, K. (1983a). Salário, preço e lucro. São Paulo: Nova Cultural.

Marx, K. (1983b). O Capital. Crítica da economia política (Vol. 1, Livro 1ํㅡ, Tomo 1). São Paulo: Abril Cultural.

Mészáros, I. (1996). O poder da ideologia. São Paulo: Ensaio.

Netto, J. P. \& Braz, M. (2007). Economia política: Uma introdução crítica. São Paulo: Cortez.

Novaes, J. R. (2007). Campeões de produtividade: Dores e febres nos canaviais paulistas. Estudos Avançados, 21(59), $167-177$.

Novaes, J. R. P., Conde, F., Maiane, R. \& Zeitune, T. (2007). Juventude e integração Sul-americana: Caracterização de situações-tipo e organizações juvenis. Relatório das situações-tipo-Brasil: Jovens migrantes canavieiros: Entre a enxada e o facão. Recuperado em 7 de maio, 2013, de http://www.ibase.br/userimages/migrantes_canavieiros_final.pdf

Oliveira, F. (2007). Prefácio. In J. R Novaes \& F. J. C Alves. (Orgs.), Migrantes: Trabalho e trabalhadores no complexo agroindustrial canavieiro (os heróis do agronegócio brasileiro) (pp. 7-9). São Carlos, SP: EdUFSCar.

Organista, J. H. C. (2006). O debate sobre a centralidade do trabalho. São Paulo: Expressão Popular.

Palhares, I. (2014, 11 de maio). Jornada de trabalho e esforço físico aumentam no campo. Folha de São Paulo, São Paulo, Caderno Cotidiano - Ribeirão Preto. Recuperada em 30 de maio, 2014, de http://www1.folha.uol.com. br/cotidiano/ribeiraopreto/2014/05/1452500-jornada-de-trabalho-e-esforco-fisico-aumentam-no-campo.shtml

Pastoral do Migrante. (2004). Rota da mobilidade humana para o interior paulista. Dossiê 2001-2003. Guariba, SP: Pastoral do Migrante.

Rosa, L. A. (2009). Trabalho e trabalhadores dos canaviais: Perfil dos cortadores de cana da região de Ribeirão Preto (SP). Monografia de Conclusão de Curso, Faculdade de Filosofia, Ciências e Letras de Ribeirão Preto, Universidade de São Paulo, Ribeirão Preto, SP.

Rumin, C. R., Navarro, V. L. \& Perioto, N. W. (2008). Trabalho e saúde no agrobusiness paulista: Estudo com colhedores manuais de cana-de-açúcar da região oeste do Estado de São Paulo. Cadernos de Psicologia Social e do Trabalho, 11(2), 193-207.

Schlesinger, S. (2008). Lenha nova para velha fornalha: A febre dos agrocombustiveis. Rio de Janeiro: FASE. Recuperado em 3 de maio, 2013, de http://www.agroeco.org/socla/pdfs/Agrocombustiveis_lenha_nova.pdf

Silva, M. A. M. (2007). Trabalho e trabalhadores na região do "Mar de Cana e do Rio de Álcool". In J. R. Novaes \& F. J. C. Alves (Orgs.), Migrantes: Trabalho e trabalhadores no complexo agroindustrial canavieiro (os heróis do agronegócio brasileiro) (pp. 55-86). São Carlos, SP: EdUFSCar.

Thomaz Júnior, A. (2002). Por trás dos canaviais os "nós" da cana: A relação capital X trabalho e o movimento sindical dos trabalhadores na agroindústria canavieira paulista. São Paulo: Annablume/FAPESP.

Triviños, A. N. S. (1987). Introdução à pesquisa em ciências sociais: a pesquisa qualitativa em educação. São Paulo: Atlas. Vettorassi, A. (2007). Partindo para a cidade garantida e proibida. In J. R. Novaes \& F. J. C. Alves (Orgs.), Migrantes: Trabalho e trabalhadores no complexo agroindustrial canavieiro (os heróis do agronegócio brasileiro) (pp. 49-156). São Carlos, SP: EdUFSCar.

Zanella, J. (2007). Os problemas do avanço da cana em SP. Jornal Unesp, 21 (228), 9.

\section{Endereço para correspondência}

psi_doug@yahoo.com.br,

vnavarro@usp.br 